\title{
Iliopsoas tendon impingement following total hip replacement surgery
}

\author{
Mr B Riemer MBChB(UCT), FCOrth(SA), FRCS Tr \& Orth(ENG) \\ Arthroplasty fellow \\ Dr M Nortje MBChB(UCT), FCOrth(SA), MMed(UCT) \\ Consultant Surgeon \\ Dr B Dower MBChB(UCT), FCOrth(SA) \\ Consultant Surgeon \\ Dr G Grobler MBChB(UCT), FCOrth(SA), MMed(UCT) \\ Consultant Surgeon \\ Department of Orthopaedics, University of Cape Town, Groote Schuur Hospital, Cape Town, South Africa
}

\author{
Corresponding author: \\ Mr Bryan Riemer \\ Department of Orthopaedics \\ Frere Hospital \\ Amalinda Road \\ 5200 East London \\ South Africa \\ Tel: +27 437092074 \\ Fax: +27437092544 \\ Cell: +27 792806894
}

\begin{abstract}
We have recently seen and successfully treated four patients with iliopsoas-related groin pain post total hip replacement. Their clinical pictures were all typical of iliopsoas-related groin pain. After the exclusion of other causes, surgical release of this tendon resulted in successful treatment with complete resolution of symptoms.

We subsequently carried out an anatomic dissection of the iliopsoas tendon on a cadaver torso to better understand the relationship between the iliopsoas tendon and the acetabular component in total hip replacement surgery. It was apparent that cup position and placement were critical to prevent contact of the iliopsoas tendon with the rim of the acetabular component. We have subsequently modified our positioning of the acetabular component.
\end{abstract}

Key words: groin pain, psoas impingement after THR

\section{Introduction}

Total hip replacement (THR) surgery is generally highly successful, with a very low complication rate. ${ }^{1,2}$ The 'forgotten hip' phenomenon describes patients who have been known to forget that they have had a hip replacement. ${ }^{3}$ Charnley pioneered the low friction arthroplasty that has become so successful in treating conditions of the hip worldwide. ${ }^{4,5}$ Joint registries from around the globe show increasing numbers of hip replacements performed year on year. ${ }^{6}$ With the incredible success of total hip replacement surgery, patients may be keen to have surgery earlier and have higher post-operative expectations. ${ }^{7}$
Hip replacement surgery is technically difficult; there are a number of crucial steps that result in a successful outcome. One of the more challenging steps in completing a successful THR is the reaming and positioning of the acetabular component. ${ }^{8}$ The aim in THR surgery is to restore the anatomic centre of rotation of the native hip joint thereby giving the muscles an optimal functioning length and restoring the biokinetics of the joint.

One of the more challenging steps in completing a successful THR is the reaming and positioning of the acetabular component 
An ideal position equates to a stable hip with a good range of movement. There should be no impingement and the hip should not dislocate. There are a multitude of techniques for obtaining the correct position of the acetabular component, from the use of a patient position orthogonal to the floor, use of the bony acetabular landmarks to guide correct placement, computer-assisted placement, the use of screening to ensure correct placement and the technique described by Beveland using the transverse acetabular ligament (TAL). ${ }^{9}$

After completion of a THR, a number of complications relating to the acetabular component may arise. These include aseptic loosening, prosthetic joint infection, associated fracture of the pelvis or complications related to malpositioning of the component, one of which is iliopsoas impingement.

\section{Iliopsoas anatomy}

The iliopsoas muscle tendon complex originates from the lumbar spine (psoas portion) and the inside of the iliac blade (iliacus portion) (Figure 1). Its primary roles are hip flexion and external rotation. The anatomy of the tendon is intimately related to the anterior acetabular rim and to the native femoral head and neck. It exits the pelvis over the pelvic brim, passes over the anterior acetabular wall, and runs over the hip joint capsule curving around the femoral neck to insert into the lesser trochanter. When replacing the hip joint one needs to pay careful attention to the anterior rim of the acetabular component to ensure that it does not protrude beyond the bony acetabulum and potentially impinge on the psoas tendon.

\section{Iliopsoas impingement: literature review}

Anterior iliopsoas impingement after THR was first reported in the literature by Trousdale et al. ${ }^{10}$ Their 1995 case report described two patients with groin pain postTHR, both with retroverted acetabular components.

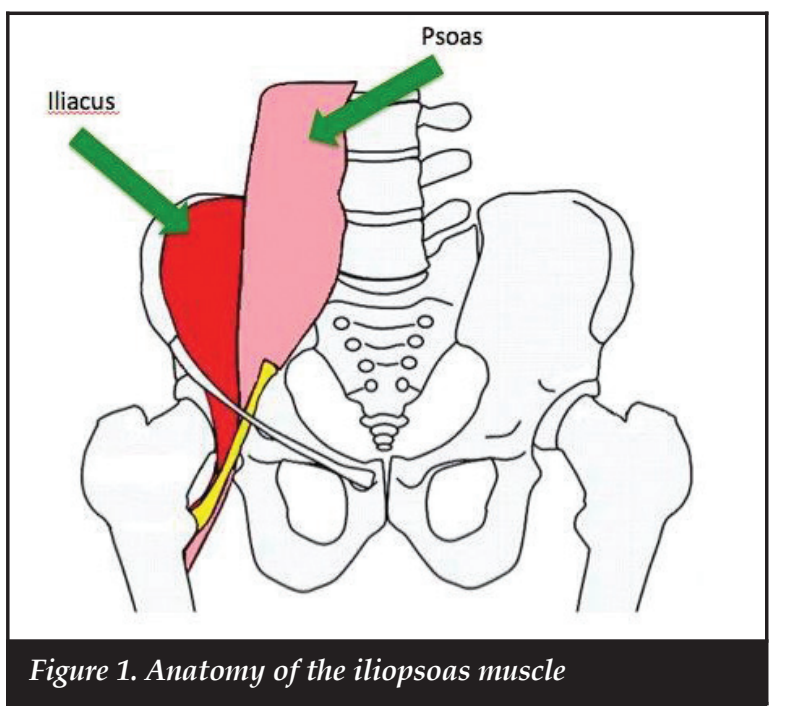

Symptoms initially responded to local anaesthetic injections and were effectively treated by acetabular revision surgery. At the time of surgery the psoas tendon was noted to be frayed.

Della Valle et al. subsequently highlighted the phenomenon of psoas impingement and suggested that simple surgical release of the tendon could potentially result in symptomatic cure. ${ }^{11}$

In 2002 Jasani et al. reported a series of nine patients with pain related to the psoas muscle after total hip replacement. ${ }^{12}$ They coined the term of the 'car sign'; a patient needs to manually lift their leg when getting out of a car. All patients responded well to CT-guided local anaesthetic injections. A surgical intervention to remove cementophytes and to trim anterior cup flanges irritating the psoas tendon was described. Two patients had uncemented cups with no obvious impingement and the authors considered an increased offset to be the cause of the irritation resulting in fibrosis of the tendon; these patients where successfully treated with lengthening tenotomies of the psoas tendon.

Similarly O'Sullivan et al. described 16 hips with iliopsoas tendonitis. ${ }^{13}$ Fifteen of 16 hips were successfully treated with a psoas tendon release and one required a revision of the acetabular cup. This was accompanied by an increase of the mean Harris Hip score from 58 to 91.

Dora et al. published a significant case series; a total of 30 hips with oversized or malpositioned acetabular components was described in 29 patients. ${ }^{14}$ All patients initially underwent a trial of conservative treatment. Eight patients then elected not to have any further surgery. Of the remaining 22 hips, six underwent a psoas tenotomy only while 16 had acetabular revision and psoas debridement. The surgical group did better overall then the non-surgical group. The acetabular revision showed no benefit over psoas release alone and had a greater number of complications. A psoas release alone was recommended for the majority of cases.

Iliopsoas impingement has also been described as a result of acetabular fixation screws penetrating the inner table of the ilium, ${ }^{15}$ from the collar of a femoral stem ${ }^{16}$ as well as from an oversized acetabular component. ${ }^{17}$ Odri recently described oversized cups as a major risk factor for postoperative pain and proved that a cup size of $6 \mathrm{~mm}$ greater than the native femoral head was a statistically significant predictor of post-operative pain after total hip replacement. ${ }^{18}$ O'Connor describes the use of a specifically designed anatomical acetabular component in a revision case for a patient with psoas impingement. ${ }^{19}$

\section{Diagnosis of iliopsoas impingement}

A number of possible diagnoses should be considered in patients presenting with groin pain following THR and a systematic approach is required to reach the correct diagnosis. The potential causes of hip pain can be classified into intra-articular, peri-articular and extra-articular causes. A detailed history and examination are fundamental prior to ordering special diagnostic investigations. 
The typical history given by patients with psoas impingement is fairly specific. Patients may present over a variable time period following THR with groin pain. The groin pain generally occurs with certain activities; pain is aggravated when climbing stairs while patients are generally pain-free when walking on the flat and at rest. They have difficulty and pain when rising from a seated position and may have difficulty and pain when climbing in or out of a car..$^{12}$ Patients also have difficulty and pain when moving the affected leg into bed. Some may also experience pain with coughing and sneezing.

A classic examination finding of patients with iliopsoas impingement is an observed difficulty in raising the affected leg to the examination couch; patients will often manually assist elevation of the leg. An active straight leg raise (SLR) may be either very painful or not possible. The passive range of movement and the passive SLR is comparatively painfree. Pain is also exacerbated by eccentric psoas contraction, for example when the raised leg is lowered to the examination couch. ${ }^{20}$

The principal role of special investigations is to exclude other causes of groin pain. Plain radiographs are important to assess the hip components for signs of loosening or infection, as this may be the cause of the groin pain. A more specific concern with regard to psoas impingement is the size and positioning of the acetabular component. Routine inflammatory markers should be performed to help determine the role of infection as a cause for groin pain; these may include a white cell count (WCC), a C-reactive protein (CRP) and an erythrocyte sedimentation rate (ESR).

A Technetium Tc-99m scintigraphy bone scan may aid in the diagnosis of infection, acetabular cup loosening, occult pelvic fracture or may highlight any other local abnormality not evident on plain radiography. ${ }^{21} \mathrm{CT}$ may aid in the delineation of acetabular component positioning and will certainly demonstrate if the antero-superior wall is prominent. CT-guided local anaesthetic injections have been employed as a psoas impingement diagnostic aid. ${ }^{12}$ A cheaper option, avoiding ionising radiation, is an ultrasound scan of the psoas tendon, which may show tendon thickening and fluid surrounding the tendon. Ultrasound can also be used for guided therapeutic or diagnostic local anaesthetic and/or steroid injections. Lastly, MRI may demonstrate tendinosis. In summary, the principal role of these specialised radiological investigations is to exclude other causes of groin pain; they should be considered on an individualised basis and may not be universally required.

\section{Treatment}

Once a diagnosis of psoas impingement has been established the treatment options may be either surgical or non-surgical. The non-surgical options include analgesia or infiltration of steroid and local anaesthetic. Iliopsoas bursal injections have been shown to be beneficial for symptomatic treatment. ${ }^{22}$ Surgical options range from simple psoas tendon release to revision of the acetabular component.
Dora et al. reflected that non-surgical management is not a permanent solution. ${ }^{14}$ No major advantage of revision surgery over tendon release was found, with a greater proportion of complications in the revision surgery group.

Psoas tendon release can be done either via an open approach or arthroscopically. Various techniques have been described for the open procedure; either via an approach used for the THR as described by Heaton in 2002 or via a separate medial approach first described by Keats. ${ }^{23,24}$ An arthroscopic release is increasingly the favoured approach with very good clinical results and no relevant weakness of hip flexion as reported by Jerosch. ${ }^{25}$

\section{Case series}

At our institution we have recently surgically treated four patients with iliopsoas impingement post THR. All four patients presented with the classic history and clinical findings as described above for iliopsoas impingement; all had groin pain, difficulty with climbing stairs, difficulty rising from a seated position, difficulty getting in and out of a car. After investigation to exclude infection and component loosening, all four patients underwent open surgical release via a medial approach as described by Taylor. ${ }^{26}$ The patients were placed supine on the operating table and the release was performed through a $5 \mathrm{~cm}$ horizontal incision approximately $2.5 \mathrm{~cm}$ below the inguinal skin crease and centred over the palpable border of the adductors. Blunt dissection is carried out in a bloodless plain between pectineus and adductor brevis medial to the femoral artery. By flexing and externally rotating the hip one brings the lesser trochanter into the surgical field, and the psoas tendon can be divided under direct vision.

\section{All four patients with iliopsoas impingement post THR underwent open surgical release via a medial approach as described by Taylor}

All patients were discharged within two days of the procedure and had immediate symptomatic relief postsurgery (Day 1). By the 3-month follow-up their symptoms had completely resolved and they had all returned to their normal activities that included golf and bowls. All four of our patients showed a dramatic improvement in their Harris hip scores. In summary none of our four patients required revision of their acetabular components and there has been no recurrence of their symptoms. In addition our patients have not complained of any loss of function due to the iliopsoas release.

Our clinical impression is that we now have significantly more patients complaining of groin pain than in the past and this may vary from an irritation to a significant loss of function. Our unit has been using an uncemented acetabular component since 1990 and has performed over 6000 cases. We initially used a Duraloc ${ }^{\circledast}$ acetabular prosthesis (DePuy Synthes, Johnson \& Johnson) which is a $160^{\circ}$ cup with the polyethylene liner protruding beyond the edge of the metal component (Figure 2). 

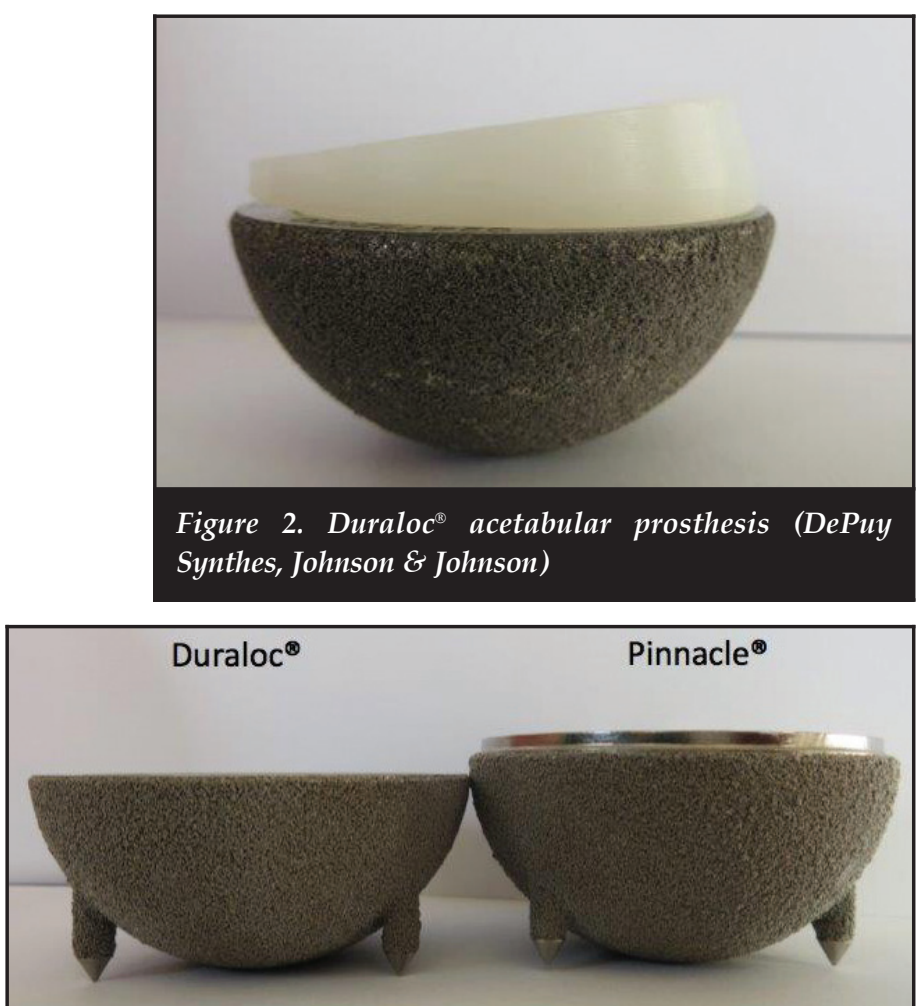

Figure 3. Comparison of Duraloc ${ }^{\oplus}$ and Pinnacle ${ }^{\oplus}$ acetabular prostheses (DePuy Synthes, Johnson \& Johnson)

Since 2010 we have been using the Pinnacle ${ }^{\circledast}$ acetabular cup system (DePuy Synthes, Johnson \& Johnson), which is a $180^{\circ}$ shell with either a ceramic or polyethylene liner seated within the confines of the component. We feel that the psoas tendon is more at risk of impingement with this $180^{\circ}$ component (Figure 3).

With the increased perceived prevalence of psoas impingement we were interested to assess the psoas tendon in a native hip and the relationship between the acetabular component position and the psoas tendon. Institutional ethics approval was obtained for anatomical dissection of a cadaveric human pelvis.

\section{Anatomical study}

Dissection revealed the intimate relationship of the femoral head, the psoas tendon and anterior wall of the acetabulum. Initial dissection illustrated how the iliopsoas tendon runs over the hip joint (Figure 4). After removing the capsule we were able to visualise how the psoas tendon glides over the anterior acetabulum and femoral head (Figure 5). After dislocation and osteotomy of the femoral neck as per THR we reamed the acetabular socket to house a Pinnacle acetabular cup system. We trialled an acetabular component to assess likely iliopsoas impingement. We found that relative anteversion of the acetabular component protects against potential iliopsoas impingement.
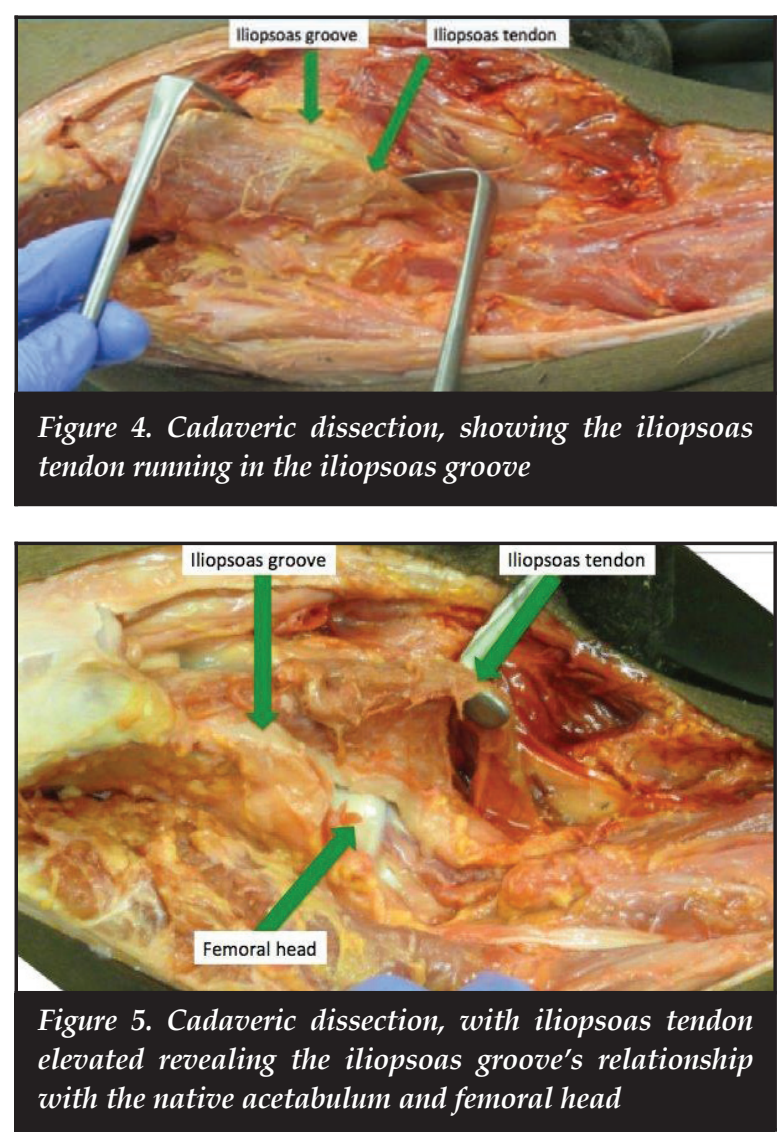

We have recognised the anterio-superior wall of the acetabulum to be an important landmark to be followed when seating the acetabular component so as to prevent iliopsoas impingement and also as a guide to version of the component being placed. As the acetabular component moves from anteversion into a retroverted position the iliopsoas tendon comes into contact with the anterio-superior rim of the acetabular component making it susceptible to impingement (Figure 6). An excessively closed neutral acetabular component will also approximate the antero-superior wall of the component to the iliopsoas tendon, increasing the risk of impingement.

We were also able to better understand how the anterio-superior rim of the acetabular component may play a role if it is not fully seated to the true floor of the acetabulum. The use of an acetabular component with spikes may result in the impaired seating and therefore bring the anterio-superior wall of the component into contact with the iliopsoas tendon. The trend towards semi-circular cups as opposed to $160^{\circ}$ cups may also have played a role in the perceived increased prevalence of iliopsoas impingement. Lastly we noted that if an oversized acetabular component was placed after over reaming, the important anterio-superior acetabular wall was breached and iliopsoas impingement more probable. ${ }^{16}$ 

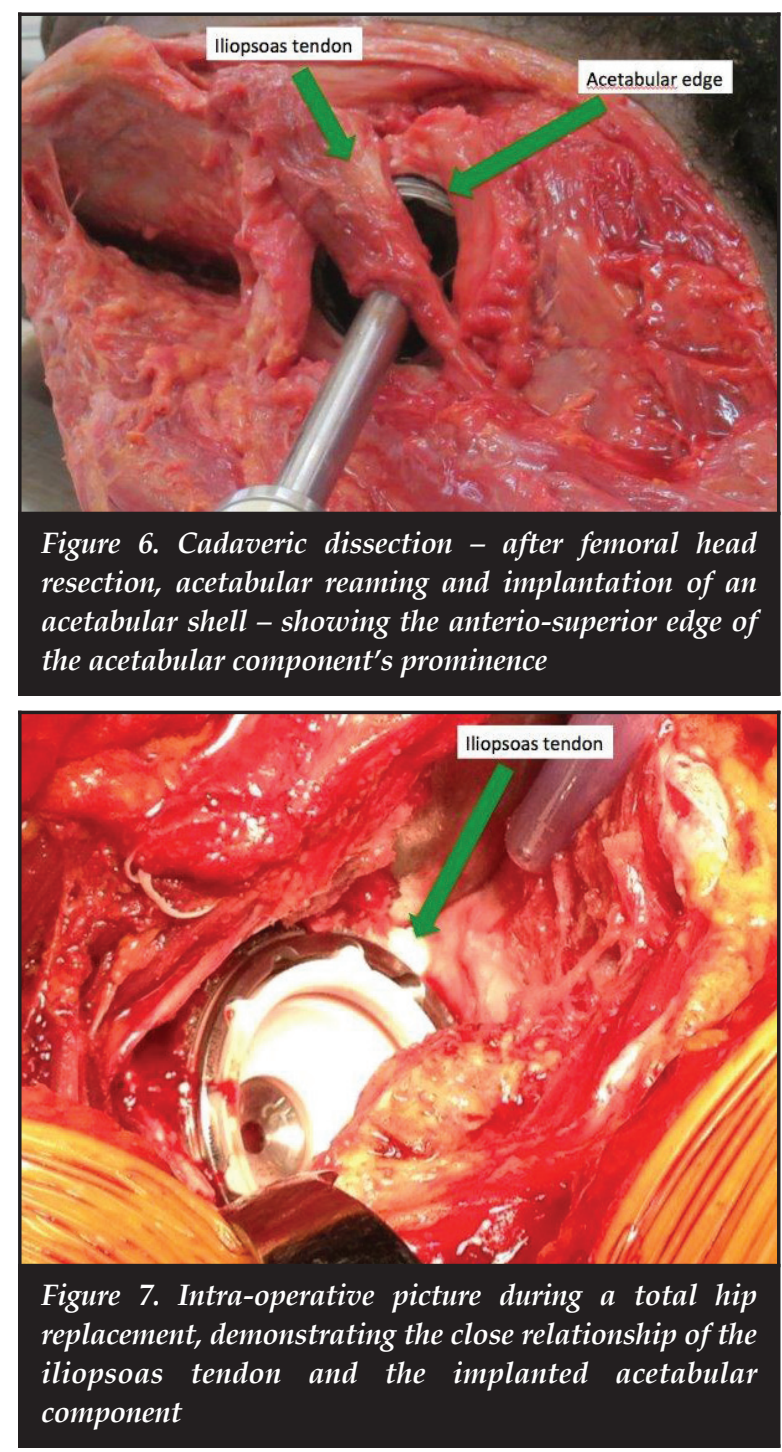

\section{Conclusion}

Total hip replacement surgery is a highly successful operation with a low complication rate. One of these unfortunate complications is groin pain associated with iliopsoas impingement at the level of the acetabular component. Correct positioning of the acetabular component can ensure that the edge of the component does not project beyond the anterio-superior wall of the acetabulum and thus minimise the possibility of impingement (Figure 7). Following this study we have modified our technique for the positioning of the acetabular component to try to avoid the possibility of our patients developing iliopsoas impingement. There are, however, circumstances when the component will be exposed due to deficient anterior acetabular wall. The only remedy in these cases may possibly be to change the design of the acetabular component edge by removing all sharp or rough surfaces.
The content of this article is the original work of the authors. This article was submitted to the University of Cape Town for Ethical Committee approval. No benefits of any form have been or are to be received from a commercial party related directly or indirectly to the subject of this article.

\section{References}

1. Belmont (Jr) PJ, Goodman GP, Hamilton W, Waterman BR, Bader JO, Schoenfeld AJ. Morbidity and Mortality in the thirty-day period following total hip arthroplasty: risk factors and incidence. J Arthroplasty 2014 May 27 (http://dx.doi.org/10.1016/j.arth.2014.05.015 Epup ahead of print).

2. Soohoo NF, Farng E, Lieberman JR, Chambers L, Zingmond DS. Factors that predict short term complication rates after total hip arthroplasty. Clin Orthop Relat Res. 2010 Sep; 468(9):2363-71 (DOI 10.1007/s11999-0101354-0).

3. Dorr LD. Editorial comment: MIS THR: Why, How and Results. VI International course in Arthroplasties, Barcelona, April 2008. Elsevier .

4. Wroblewski BM, Siney PD, Fleming PA. The Charnley Hip Replacement- 43 Years of Clinical Success. Acta Chir Orthop Traumatol Cech. 2006;73(1):6-9.

5. Charnley J. The long-term results of Low-friction arthroplasty of the hip performed as a primary intervention. $J$ Bone Joint Surg Br. 1972 Feb;54(1):61-76.

6. No authors listed. National Joint Registry for England and Wales $10^{\text {th }}$ Annual Report, 2013. www.njrcentre.org.uk. 1 June 2014.

7. Learmonth ID, Young C, Rorabeck C. The operation of the century: total hip replacement. Lancet 2007 Oct 27;370(9597):1508-19.

8. Lee Y-K, Biau DJ, Yoon B-H, Kim T-Y, Ha Y-C, Koo K-H. Learning curve of acetabular cup positioning in total hip arthroplasty using a cumulative summation test for learning curve (LC-CUSUM). J Arthroplasty 2014 Mar;29(3):586-89.

9. Archbold HAP, Mockford B, Molloy D, McConway J, Ogonda L, Beveland D. The transverse acetabular ligament: an aid to orientation of the acetabular component during primary total hip replacement. J Bone Joint Surg Br 2006 Jul;88(7):883-86.

10. Trousdale RT, Cabanela ME, Berry DJ. Anterior iliopsoas impingement after total hip arthroplasty. J Arthroplasty 1995 Aug;10(4):546-49.

11. Della Valle CJ, Rafii M, Jaffe WL. Iliopsoas tendinitis after total hip arthroplasty. J Arthroplasty 2001 Oct;16(7):923-26.

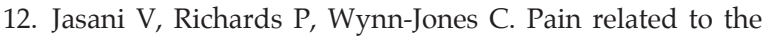
psoas muscle after total hip replacement. J Bone Joint Surg Br 2002 Sep;84(7):991-93.

13. O'Sullivan M, Richards S, Skyrme AD et al. Iliopsoas tendonitis a complication after total hip arthroplasty. J Arthroplasty 2007 Feb;22(2):166-70.

14. Dora C, Houweling M, Koch P, Sierra RJ. Iliopsoas impingement after total hip replacement: The results of non-operative management, tenotomy or acetabular revision. J Bone Joint Surg Br 2007 Aug;89(8):1031-35. 
15. Mayne IP, Kosashvili Y, White LM et al. Iliopsoas tendonitis due to the protrusion of an acetabular component fixation screw after total hip arthroplasty. J Arthroplasty 2010 Jun;25(4):659.e5-8.

16. Brew CJ, Stockley I, Grainger AJ, Stone MH. Iliopsoas tendonitis caused by overhang of a collared femoral prosthesis. J Arthroplasty 2011 Apr;26(3):504.e17-19.

17. Abbas AA, Kim YJ, Song EK, Yoon TR. Oversized acetabular socket causing groin pain after total hip arthroplasty. J Arthroplasty 2009 Oct;24(7):1144.e5-8.

18. Odri GA, Padiolleau GB, Gouin FT. Oversized cups as a major risk factor of postoperative pain after total hip arthroplasty. J Arthroplasty 2014 April;29(4) 753-56.

19. O'Connor MI. Use of an anatomical acetabular component for treatment of iliopsoas impingement: case report. $J$ Arthroplasty 2011 Dec;26(8):1570.e13-15.

20. Henderson RA, Lachiewicz PF. Instructional Review: Hip. Groin pain after replacement of the hip. Aetiology, evaluation and treatment. J Bone Joint Surg Br. 2012 Feb;94(2):145-51

21. Lachiewicz PF, Kauk JR. Anterior iliopsoas impingement and tendinitis after total hip arthroplasty. I Am Acad Orthop Surg 2009 Jun;17(6):337-44.
22. Nunley RM, Wilson JM, Gilula L, Clohisy JC, Barrack RL and Maloney WJ. Iliopsoas bursa injections can be beneficial for pain after total hip arthroplasty. Clin Orthop Relat Res. 2010 Feb;468(2):519-26.

23. Heaton K, Dorr LD. Surgical release of iliopsoas tendon for groin pain after total hip arthroplasty: technical note. J Arthroplasty 2002 Sep;17(6):779-81.

24. Keats S, Morgese AN. A simple anteromedial approach to the lesser trochanter of the femur for the release of the iliopsoas tendon. J Bone Joint Surg Am. 1967 Jun;49(4):63236.

25. Jerosch J, Neuhauser C, Sokkar SM. Arthroscopic treatment of iliopsoas impingement (IPI) after total hip replacement. Arch Orthop Trauma Surg 2013 Oct;133(10):1447-54.

26. Taylor GR, Clarke NMP. Surgical release of the 'snapping iliopsoas tendon'. J Bone Joint Surg Br. 1995 Nov;77(6):88183.

This article is also available online on the SAOA website (www.saoa.org.za) and the SciELO website (www.scielo.org.za). Follow the directions on the Contents page of this journal to access it. 